\title{
Fertility Enhancement in Rabbits using Growth Hormone Agonist (Adenosine)
}

\author{
Hanan SALEH ${ }^{1}$, T.A.E. El-Kasas ${ }^{2}$, A.M. SAEed ${ }^{3}$
}

${ }^{1}$ Zoology Department, Faculty of Science, Cairo University, 12316, Giza, Egypt; ${ }^{2}$ Department of Animal Biotechnology, Animal Production Research Institute, 12816, Dokki, Giza, Egypt; ${ }^{3}$ Animal Biotechnology, Animal Production Research Institute, 12816, Dokki, Giza, Egypt.

\begin{abstract}
The aim of this study was to evaluate the effect of adenosine to improve the fertility of male rabbits. A total of 36 adults red Baladi breed rabbits were divided into two main groups, pre puberty and post puberty groups. Each group was then subdivided into subgroups that received a low dose $(0.4 \mathrm{mg} / \mathrm{kg})$ and high dose $(0.8 \mathrm{mg} / \mathrm{kg})$ of adenosine injection intravenously in ear vein daily for 3 months. Bucks that received a high dose $(0.8 \mathrm{mg})$ of adenosine had a higher ejaculate volume, mass motility, sperm concentration, total sperm output and total motile sperm in both pre and post puberty groups. High dose of adenosine caused a significant increase in testosterone levels in pre and post puberty groups. Moreover, administration of adenosine to pre puberty rabbits could increase the high rate of cells differentiation more than those in other groups. Practically, it could be recommended that a high dose of adenosine is an appropriate supplement for improving semen quality, reproductive abilities and the economic efficiency of rabbit bucks.
\end{abstract}

Keywords | Adenosine, Growth hormone, Puberty, Testosterone, Rabbits

Received | June 25, 2019; Accepted | August 19, 2019; Published | November 26, 2019

*Correspondence | Hanan Saleh, Zoology Department, Faculty of Science, Cairo University, 12316, Giza, Egypt; Email: heead@sci.cu.edu.eg

Citation | Saleh H, El-Kasas TAE, Saeed AM (2019). Fertility enhancement in rabbits using growth hormone agonist (adenosine). Adv. Anim. Vet. Sci. 7(12): 1107-1112.

DOI | http://dx.doi.org/10.17582/journal.aavs/2019/7.12.1107.1112

ISSN (Online) | 2307-8316; ISSN (Print) | 2309-3331

Copyright (C) 2019 Saleh et al. This is an open access article distributed under the Creative Commons Attribution License, which permits unrestricted use, distribution, and reproduction in any medium, provided the original work is properly cited.

\section{INTRODUCTION}

$\mathrm{R}$ abbits are mammals with a great economic value, where they consume small amount of food to produce meat with a higher percentage of protein (20\%) and good taste. Rabbit meat is easy to digest, has lees fat (11-20\%) and less caloric value (795) and rich with minerals. In addition, rabbits are being short cycle animals, don't need wide places for breeding and don't compete human in their food (Peckham et al., 2006). Developing and preserving maximum reproductive efficacy in rabbits is vital to the economy of the rabbit industry.

Sexual puberty is considered as one of the most essential parameters affecting the reproductive competence of farm animals (Morampudi et al., 2014). He stated that early puberty and high initial fertility may be good bases for economic selection.

Several endocrine factors are associated with growth and metabolism could stimulate various actions leading to $\mathrm{pu}^{-}$ berty or gamete production. There is considerable clinical and experimental evidence that growth hormone $(\mathrm{GH})$ and testosterone have multiple interactions. Growth hormone $(\mathrm{GH})$ is an important anabolic hormone, is a peptide hormone that stimulates growth, cell reproduction and regeneration in humans and other animals (Zhou et al., 2017). GH treatment increases serum testosterone level, Luteinizing hormone receptor (LH), motility of sperm and sensitivity of pituitary gland to Gonadotropin-releasing hormone $(\mathrm{GnRH})$ from hypothalamus (Tsai, 2006). $\mathrm{GH}$ increases androgen secretion during puberty, stimulates testis differentiation of its germinal cells, increases sensitivity of testis for Follicle-stimulating hormone (FSH), $\mathrm{LH}$ and testosterone and initiate the process of spermatogenesis (Chandrashekar and Bartke, 2003).

Growth hormone secretagogues (GHSs) are synthetic compounds that induce GH release (Xin et al., 2006). Moreover, a new class of GH secretagogingues (GHSs) based on small synthetic peptides that induce $\mathrm{GH}$ release called hypothalamic GHS receptor (GHS-R) agonists. Among these agonists there is a naturally compound occurred in the body called adenosine (Tullin et al., 2000). 
Adenosine, a purine nucleoside generated by the de-phosphorylation of adenine nucleotides, is a potent endogenous physiologic and pharmacologic regulator of many functions (Cronstein and Haskó, 2013). Adenosine plays an important role in anabolic reactions of biochemical process, such as: Joining transfer RNA to amino acids for assembly into proteins, It shared on synthesis of polysaccharides and fats, It is of vital role in nerve impulses, muscle contraction and beating of cilia (including sperm) (Haskó and Cronstein, 2004). Adenosine triphosphate (ATP) one of the monomers used in the synthesis of RNA and DNA (Lowery and Richardson, 1977). Due to the important roles of adenosine in stimulating of pituitary gland to secrete growth hormone in blood flow to target cells, safety for administration, and is of low price with high solubility in water. So we can use adenosine as source for GH inside the animal body (Weyler et al., 2006). This study was performed to investigate the effect of intravenous adenosine injection in -pre and post puberty rabbits on semen characteristics, testosterone level and histological examinations of rabbit bulls.

\section{MATERIALS AND METHODS}

\section{Chemicals}

All chemicals except testosterone were purchased from Sigma-Aldrich (S.A., Egypt).

\section{Animals and Ethics Statement}

A total of 36 rabbit bucks belonging to red Baladi breed (Khalil and Baselga, 2002) were purchased from the rabbit farm stations of Animal Production Research Institute (APRI, Cairo, Egypt). All does and bucks were housed during the study period in a semi-closed rabbitry housing system (Agricultural Experiment Station, Faculty of Agriculture, Cairo University) and kept in batteries of individual cages $(60 \times 50 \times 35 \mathrm{~cm})$, supplied with feeding hoppers made of galvanized steel sheets and nipples for automatic drinker. They were maintained under the same standard environmental conditions with light alternating on a cycle of 16 light hours and 8 dark hours, fed with the same commercial diet (18.4\% CP, 3.1\% ether extract, $12.7 \%$ crude fiber and $2.600 \mathrm{kcal} \mathrm{DE} / \mathrm{kg}$ ) and had free access to water. All the experimental protocols were approved by the Research Ethics Committee at the, KafrElSheikh University, Egypt.

\section{Semen and Blood Collection}

Semen was collected using the artificial vagina once each 10 days. Physical characteristics (ejaculate volume, mass motility percentage, live percentage, and abnormal sperm percentage and sperm concentration) of rabbit's semen were evaluated immediately after collection. Analysis of semen samples was recorded only after 50 days from the beginning of the treatment. Blood samples were collected once a week from the ear vein of the rabbits and placed immediately on ice in heparinized tubes. Serum was collected from blood by centrifugation at $860 \mathrm{Xg}$ for $20 \mathrm{~min}$ at $4{ }^{\circ} \mathrm{C}$ and stored at $-60^{\circ} \mathrm{C}$. By the end of the experiment, two rabbits from each group were randomly chosen and slaughtered to study the histological changes in testis (Attia et al., 2013).

\section{ExPERIMENTAL DESign}

A total of 36 rabbit bucks belonging to red Baladi breed were used in this experiment. They were divided into two main groups eighteen each. The first group aged four months (pre puberty) and the average weight was $1.78 \mathrm{Kg}$. Meanwhile, the second one aged six months (post puberty) in which scrotum can clearly be seen, and the average weight was $2 \mathrm{~kg}$ at the beginning of the study. Each group was divided randomly and equally to 3 subgroups according to the level of adenosine injection (low dose, high dose and control). Adenosine was injected intravenously in ear vein by $0.4 \mathrm{mg} / \mathrm{kg}$ (low dose) and $0.8 \mathrm{mg} / \mathrm{kg}$ (high dose) which was dissolved in $1 / 2 \mathrm{ml} 0.9 \mathrm{NaCl}$ every day for 3 months to each subgroup. The third subgroup (control) was injected by $0.5 \mathrm{ml}$ normal saline $0.9 \mathrm{NaCl}$.

\section{Testosterone Assessment}

Serum concentration of testosterone was measured as testosterone enzymes immune-assay commercial test kit catalog number: BC-115 (Biocheck Inc, CA, USA). Testosterone (17 $\beta$ - hydroxyl androst-4-ene-3-one).

\section{Statistical Analysis}

The data were analyzed using the general linear model procedure program (SPSS for windows 19.0, SPSS Inc, Chicago, USA). Differences among experimental groups were tested by One Way ANOVA with Duncan's Multiple Range test to test the significance. P-values 0.05 were accepted as significant.

\section{RESULTS}

The ejaculate volume pre puberty (Table 1 ) showed significant increase $(\mathrm{P}<0.05)(1.1 \mathrm{ml})$ in high dose group compared to control one $(0.8 \mathrm{ml})$. While no significant difference was obtained post puberty between all groups. Sperm motility percent increased significantly $(\mathrm{P}<0.05)$ in low and high dose groups pre and post puberty (79.3 and 83.0 vs 80.3 and 79.0 , respectively) compared to control groups (72.0 vs. 75.0, respectively). Numbers of live sperms and the concentration were increased significantly $(\mathrm{P}<0.05)$ in pre and post puberty with low and high doses of adenosine compared to control groups, on contrary the numbers of sperm abnormalities decreased in both groups.

The effect of adenosine injection on testosterone concentr- 
Table 1: Effect of adenosine on physical characteristics of rabbits' semen

\begin{tabular}{lllllll} 
& \multicolumn{3}{c}{ Pre puberty } & \multicolumn{3}{c}{ Post puberty } \\
Semen traits & Control & Low dose & High dose & Control & Low dose & High dose \\
\hline Volume (ml) & $0.8^{\mathrm{b}} \pm 0.1$ & $0.9^{\mathrm{ab}} \pm 0.1$ & $1.1^{\mathrm{a}} \pm 0.1$ & $1.0^{\mathrm{ab}} \pm 0.1$ & $0.9^{\mathrm{a} b} \pm 0.1$ & $1.0^{\mathrm{ab}} \pm 0.1$ \\
Motility (\%) & $72.0^{\mathrm{b}} \pm 1.2$ & $79.3^{\mathrm{a}} \pm 1.2$ & $83.0^{\mathrm{a}} \pm 1.2$ & $75.0^{\mathrm{b}} \pm 1.2$ & $80.3^{\mathrm{a}} \pm 1.2$ & $79.0^{\mathrm{a}} \pm 1.2$ \\
\hline Live (\%) & $75.3^{\mathrm{b}} \pm 1.2$ & $83.0^{\mathrm{a}} \pm 1.2$ & $86.0^{\mathrm{a}} \pm 1.2$ & $77.0^{\mathrm{b}} \pm 1.2$ & $85.0^{\mathrm{a}} \pm 1.2$ & $85.0^{\mathrm{a}} \pm 1.2$ \\
Abnormalities (\%) & $10.2^{\mathrm{a}} \pm 0.4$ & $6.3^{\mathrm{b}} \pm 0.4$ & $5.6^{\mathrm{b}} \pm 0.4$ & $10.1^{\mathrm{a}} \pm 0.4$ & $6.5^{\mathrm{b}} \pm 0.4$ & $6.0^{\mathrm{b}} \pm 0.4$ \\
\hline Concentration Million/ml & $492.0^{\mathrm{e}} \pm 8.6$ & $604.0^{\mathrm{bc}} \pm 8.6$ & $648.0^{\mathrm{a}} \pm 8.6$ & $520.0^{\mathrm{d}} \pm 8.6$ & $582.0^{\mathrm{c}} \pm 8.6$ & $617.0^{\mathrm{b} \pm 8.6}$
\end{tabular}

$\mathrm{a}, \mathrm{b}$ means having different superscripts within the same row differ significantly $(\mathrm{P}<0.05)$.

Low dose refers to group injected by $0.4 \mathrm{mg}$ of adenosine

High dose refers to injected by $0.8 \mathrm{mg}$ of adenosine

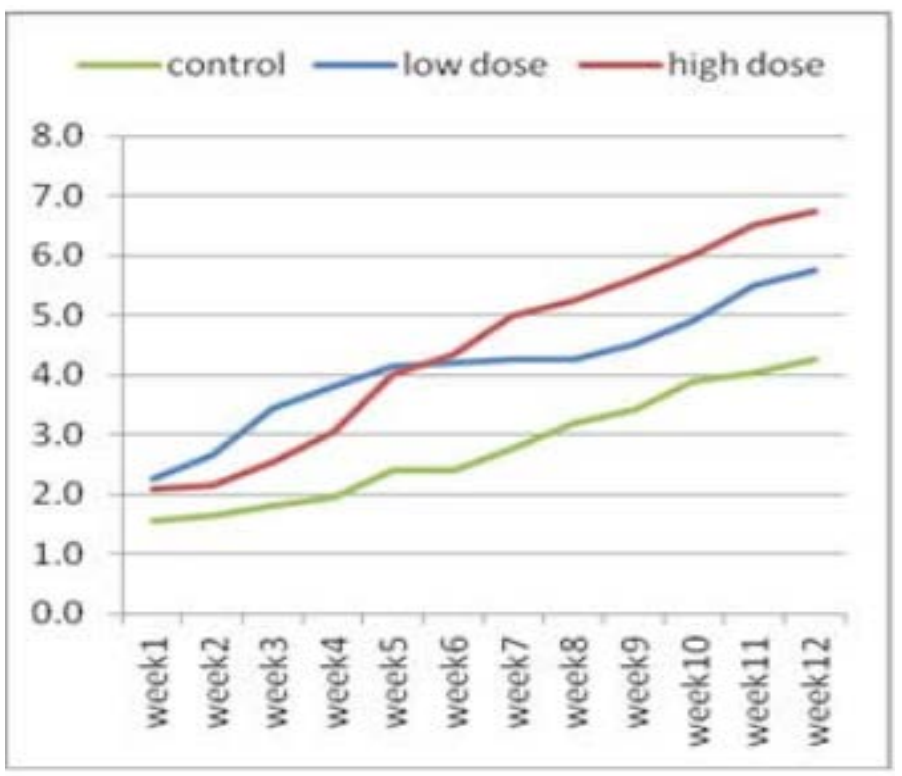

Figure 1: Effect of adenosine injection for twelve weeks on testosterone concentration $(\mathrm{ng} / \mathrm{ml})$ of rabbit males (pre puberty).

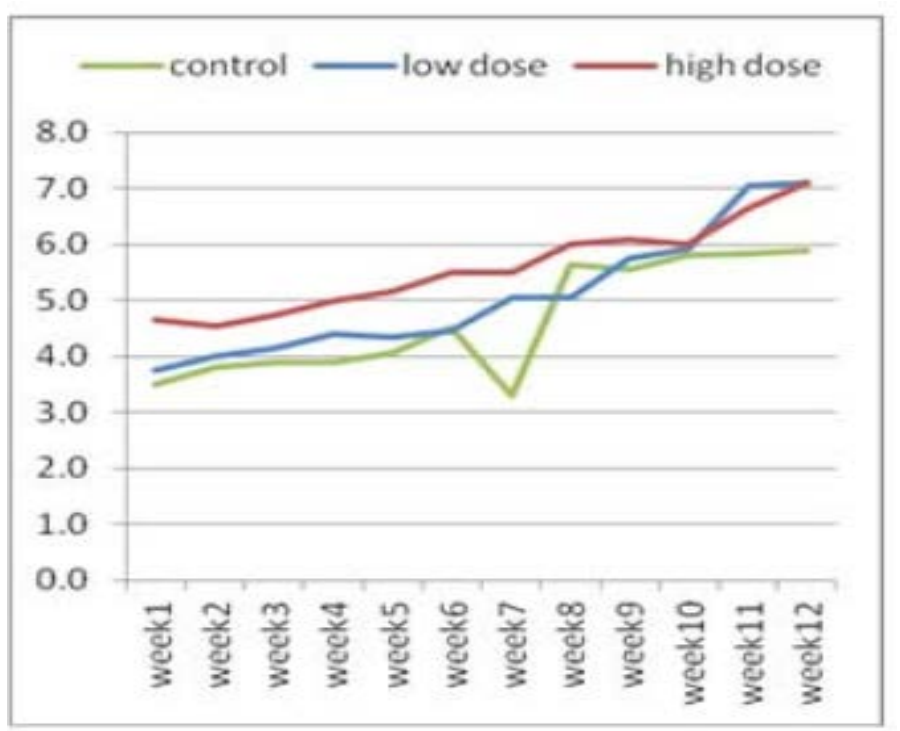

Figure 2: Effect of adenosine injection for twelve weeks on testosterone concentration $(\mathrm{ng} / \mathrm{ml})$ of rabbit males (post puberty) ation $(\mathrm{ng} / \mathrm{ml})$ for 12 weeks showed in (Figure 1 and 2). Pre-pubertal buck's revealed insignificant increase in testosterone concentration with lower dose $(2.25 \pm 0.21)$ of adenosine compared to higher dose $(2.10 \pm 0.21)$ and control subgroups $(1.55 \pm 0.21)$ after 1 st wk (Figure 1). Testosterone concentration increased significantly and gradually with low doses compared to high doses and control from the second week to the fourth week. From the seventh week to the end of the experiment, testosterone concentration increased significantly in the first subgroup (high dose) compared to low dose and control subgroups, respectively (Figure 1). The concentration of testosterone showed insignificant increase (Figure 2) during first six weeks using high doses of adenosine compared to other subgroups.

\section{The Effect of Adenosine on Testis Tissues}

The histological examination of testis tissue of rabbits injected with adenosine for 12 weeks in the pre puberty groups injected with (low and high doses of adenosine (Figure $3 \mathrm{~A}$ and $\mathrm{C}$ ) showed numerous seminiferous tubules with complete maturation and differentiation of spermatogenic cells from spermatogonia up to spermatozoa more than the corresponding control group (Figure $3 \mathrm{E}$ ) which is of slow level of differentiation of spermatogonia and few number of spermatozoa (sp) in their lumen and a wide interstitial spaces (IS). Post puberty groups of rabbits injected with low and high doses of adenosine (Figure 3B and 3D) respectively, revealed all stages of spermatogenesis as spermatogonia, spermatocyte (sc), spermatids (sd), and spermatozoa (sp). The interstitial spaces (Is) with interstitial cells of leydig (IT) responsible for production of testosterone were seen. The pre puberty rabbits injected with high dose of adenosine (Figure 3C) showed high rate of differentiation more than those in other groups which have aggregation of sperms (sp) in the patent lumen $(t)$ of semineferous tubules. The post puberty control group (Figure $3 \mathrm{~F}$ ) showed normal structure of seminiferous tubules lined by stratified germinal epithelium (GE). In their lumen few aggregation of sperms (sp) and wide interstitial spaces (Is) were seen with few clusters of interstitial cells (IT) and a few number of spermatozoa than the other groups. 


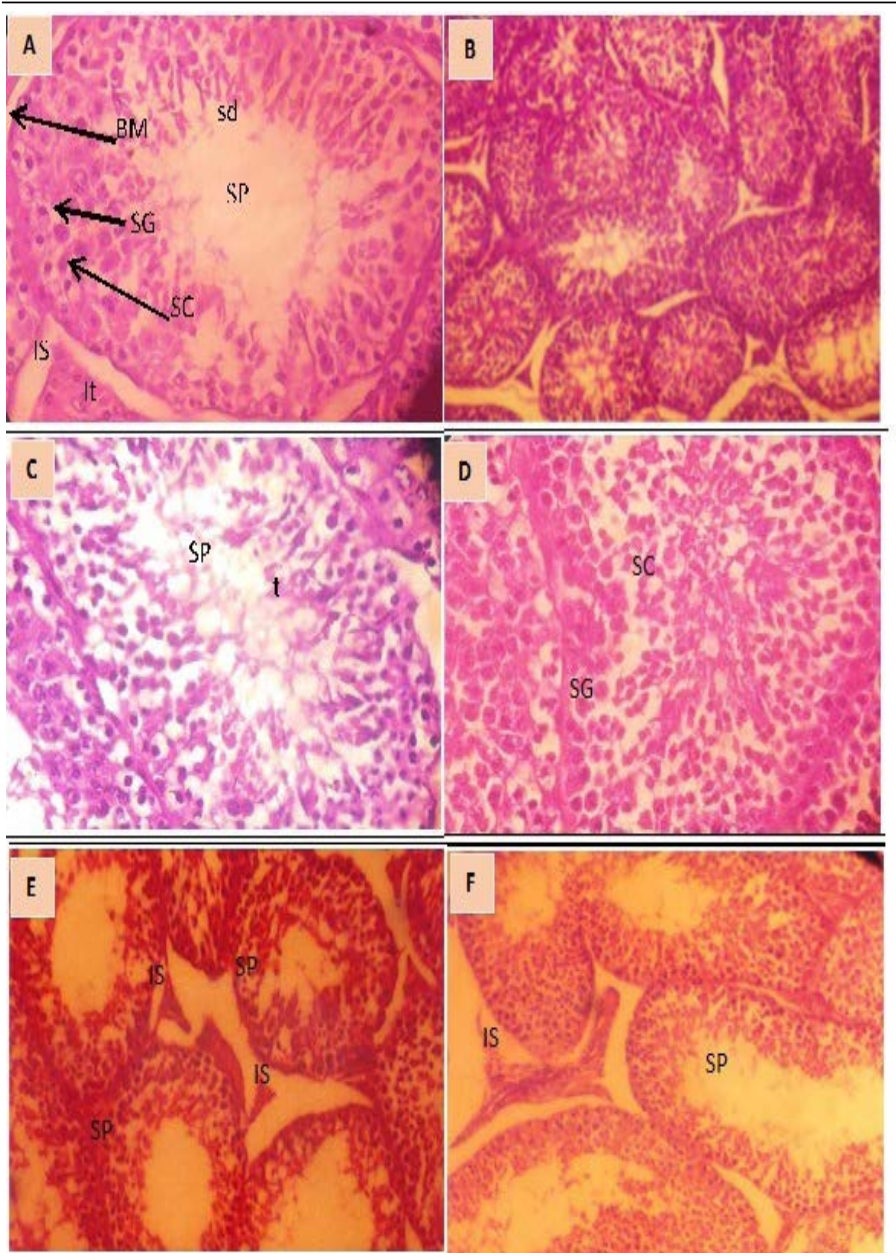

Figure 3: Cross section in the testis of male rabbit. 3A. (pre puberty) treated with of adenosine (low dose) revealing all stages of spermatogenesis. a) spermatogonia (SG) resting on basement membrane (BM), spermatocyte (SC), spermatids (sd) spermatozoa (SP), interstial space and Interstitial cells of leydig (IT) . (x 400). 3B. Cross section in the testis of rabbit male (Post-puberty) treated with adenosine (low dose) showing numerous seminiferous tubules with complete maturation and differentiation of spermatogenic cells from spermatogonia up to spermatozoa (sp). (x 100). 3C. High power view (x400) of the section in the testis of rabbit male (pre puberty) treated with of adenosine (high dose) demonstrating all stages of spermatogenesis, seminiferous tubules with patent lumen $(\mathrm{t})$ having aggregation of sperms $(\mathrm{SP})$ were seen. 3D. High power view $(\mathrm{x} 400)$ of the section in the testis of rabbit male (post-puberty) treated with adenosine (high dose) showing normal testicular structure complete maturation and differentiation of spermatogenic cells, spermatogonia $(\mathrm{SG})$ and spermatocyte (SC). 3E. Section in testis of pre puberty rabbit male (control group) showing somewhat normal structure of seminiferous tubules lined by stratified germinal epithelium (GE). In their lumen few aggregation of sperms (sp) and wide interstitial spaces are seen (Is) with few clusters of interstitial cells (IT). (x100). 3F. Section in testis of (post-puberty) rabbit male (control group) showing seminiferous tubules with maturation up to spermatids, with presence of few numbers of spermatozoa
(SP) in their lumen and a wide interstitial spaces (IS).(x 100)

\section{DISCUSSION}

The process of spermatogenesis is regulated by a complex interaction of endocrine and paracrine signals. The master control hormone is gonadotropin releasing hormone $(\mathrm{GnRH})$, produced by specialized neurons in the hypothalamus. Pulsatile GnRH production signals gonadotroph cells in the anterior pituitary to produce follicle-stimulating hormone (FSH) and luteinizing hormone (LH) that then act on the testis to regulate spermatogenic potential. LH binds to receptors on the surface of Leydig cells in the testis and stimulates the production of testosterone, a steroid hormone that diffuses into the seminiferous tubules (Walker and Cheng, 2005). Testosterone the main circulating androgen of testicular origin, has a vital role in maintaining libido, body fat, maintaining muscle mass, bone density and the regulation of blood sugar (Vignozzi et al., 2012).

The Adenosine regeneration is very important for maintaining sperm motility for a long time. So this work is focusing on the improvement of rabbit fertility by the administration of adenosine. Previous study indicated that enhancement of semen quality in male rabbits treated with royal jelly (RJ) could be associated with higher concentration of testosterone particularly libido of bucks, ejaculate volume and seminal plasma fructose which are testosterone dependent process (Khadr et al., El-Hanoun et al., 2014). (Hafez and Hafez, 2013) also stated that fructose synthesis by the accessory sex glands was dependent on the secretion of testosterone hormone by Leydig cells of testis. The observed improvement in sperm motility is consistent with the findings of (Elnagar, 2010), who reported higher sperm motility when male mice were treated with RJ. The significant increase in sperm-cell concentration can be explained by the findings of (Kohguchi et al., 2007), who demonstrated that golden hamster treated with RJ showed more intensive spermatogenesis than untreated group. Similar observations were recorded by (Karacal and Aral, 2008), who reported higher sperm concentration when male mice were treated with RJ. (ElKelawy, 1995), reported that ejaculate volume, sperm motility and sperm concentration were significantly increased when male rabbits treated with testosterone. This findings, agrees with the work of (Bandaranayake, 2002) who reported that some supplements and extracts are used to enhance reproduction in male rabbits.

The present study showed that the administration of adenosine revealed all stages of spermatogenesis as spermatogonia, spermatocyte (sc), spermatids (sd), and spermatozoa (sp). The interstitial spaces (Is) with interstitial cells of 
leydig (IT) that are responsible for production of testosterone. ATP, proved to be an extraordinarily stimulating natural activator of sperm cells (Foresta et al., 1992). Previously, (De Lamirande and Gagnon, 1991) were revealed that sperm motility of intact spermatozoa decreased when their ATP concentration was reduced. The mammalian sperm must be highly motile for a long time to fertilize the egg so, ATP is required for sperm motility (Mukai and Okuno, 2004). During establishment of puberty growth hormone pulse amplitude and frequency increase rapidly, coinciding with an increase of nocturnal testosterone levels (Wennink et al., 1990).

\section{CONCLUSION}

The results of the present study revealed that the high dose of adenosine caused a significant increase in the volume, percent of motility and live sperm, in addition to the testosterone levels in pre and post puberty groups. Moreover, administration of adenosine to pre puberty rabbits could increase the high rate of cells differentiation more than those in other groups. Practically, it could be recommended that high dose of adenosine is an appropriate supplement for improving semen quality, reproductive traits and the economic efficiency of rabbit bucks.

\section{ACKNOWLEDGEMENTS}

Authors would like to thank Department of Animal Biotechnology, Animal Production Research Institute for providing all the facilities for this research.

\section{CONFLICT OF INTEREST}

The authors report that there is no conflict of interest.

\section{AUTHORS CONTRIBUTION}

AM Saeed: Conceived and designed the experiments. T.A.E. E1-Kasas: Performed the experiments and analyzed the data. AM Saeed and T.A.E. El-Kasas: Contributed reagents/materials/analysis tools. Hanan Saleh. Wrote the paper.

\section{REFERENCES}

-Attia Y, EA El Hamid, A Ismaiel, A El-Nagar (2013). The detoxication of nitrate by two antioxidants or a probiotic, and the effects on blood and seminal plasma profiles and reproductive function of New Zealand White rabbit bucks. Animal. 7(4): 591-601. https://doi.org/10.1017/ S1751731112002054

-Bandaranayake WM (2002). Bioactivities, bioactive compounds and chemical constituents of mangrove plants. Wetlands Ecol. Manag. 10(6): 421-452. https://doi. org/10.1023/A:1021397624349

- Chandrashekar V, A Bartke (2003). The role of insulinlike growth factor-I in neuroendocrine function and the consequent effects on sexual maturation: inferences from animal models. Reprod. Biol. 3(1): 7-28.

- Cronstein BN, G Haskó (2013). Regulation of inflammation by adenosine. Frontiers in immunology 4: 85 https://doi. org/10.3389/fimmu.2013.00085.

-De Lamirande E, C Gagnon (1991). Reactive oxygen species and human spermatozoa. II. Depletion of adenosine triphosphate plays an important role in the inhibition of sperm motility. J. Androl. 13(5): 379-386.

-El-Hanoun A, A Elkomy, W Fares, E Shahien (2014). Impact of royal jelly to improve reproductive performance of male rabbits under hot summer conditions. World Rabbit Sci. 22(3): 241-248. https://doi.org/10.4995/wrs.2014.1677

-ElKelawy HM, Aboulnaga AI, El-Kelawy HM (1995). Effect of testosterone treatment on reproductive efficiency of growing and poor fertile male rabbits. Egypt. J. Rabbit Sci. 5(2): 89-100.

-Elnagar SA (2010). Royal jelly counteracts bucks'“summer infertility”. Anim. Reprod. Sci. 121(1-2): 174-180. https:// doi.org/10.1016/j.anireprosci.2010.05.008

- Foresta C, M Rossato, F Di Virgilio (1992). Extracellular ATP is a trigger for the acrosome reaction in human spermatozoa. J. Biolog. Chem. 267(27): 19443-19447.

- Hafez ESE, B Hafez (2013). Reproduction in farm animals, John Wiley \& Sons.

- Haskó G, BN Cronstein (2004). Adenosine: an endogenous regulator of innate immunity. Trends Immunol. 25(1): 3339. https://doi.org/10.1016/j.it.2003.11.003

- Karacal F, F Aral (2008). Effect of the royal jelly on sperm quality in mice. Indian Vet. J. 85(3): 331-332.

-Khadr A, A Abdou, A El-Sherbiny Age of puberty and fertility of male new zealand white rabbits orally administered with royal jelly or/and bee honey.

- Khalil M, M Baselga (2002). Rabbit genetic resources in Mediterranean countries. Options Méditerranéennes. Série B: Etudes et Recherches. (CIHEAM).

-Kohguchi, M., S.-I. Inoue, S. Ushio, K. Iwaki, M. Ikeda And M. Kurimoto (2007). Effect of royal jelly diet on the testicular function of hamsters. Food Sci. Technol. Res. 10(4): 420423. https://doi.org/10.3136/fstr.10.420

-Lowery, C. and J. Richardson (1977). Characterization of the nucleoside triphosphate phosphohydrolase (ATPase) activity of RNA synthesis termination factor p. II. Influence of synthetic RNA homopolymers and random copolymers on the reaction. J. Biolog. Chem. 252(4): 1381-1385.

-Morampudi V, G Bhinder,XWu, C Dai, HP Sham, BA Vallance, K Jacobson (2014). DNBS/TNBS colitis models: providing insights into inflammatory bowel disease and effects of dietary fat.J. Visualized Exper. (84): e51297-e51297.https:// doi.org/10.3791/51297

- Mukai C, M Okuno (2004). Glycolysis plays a major role for adenosine triphosphate supplementation in mouse sperm flagellar movement. Biol. Reprod. 71(2): 540-547. https:// doi.org/10.1095/biolreprod.103.026054

-Peckham JC, SC Gad, CM Salamon, KM MacKenzie (2006). The Rabbit. Animal Models in Toxicology, Second Edition, Informa Healthcare: 421-492.

-Tsai PS (2006). Gonadotropin-releasing hormone in 
invertebrates: structure, function, and evolution. General Comparat. Endocrinol. 148(1): 48-53. ogy 148(1): 48-53. https://doi.org/10.1016/j.ygcen.2005.09.016

-Tullin S, BS Hansen, M Ankersen, J Møller, KA von Cappelen, L Thim (2000). Adenosine is an agonist of the growth hormone secretagogue receptor. Endocrinology. 141(9): 3397-3402. https://doi.org/10.1210/endo.141.9.7631

-Vignozzi L, A Morelli, E Sarchielli, P Comeglio, S Filippi, I Cellai, E Maneschi, S Serni, M Gacci, M Carini (2012). Testosterone protects from metabolic syndrome-associated prostate inflammation: an experimental study in rabbit. J. Endocrinol. 212(1): 71-84. https://doi.org/10.1530/JOE11-0289

-Walker WH, J Cheng (2005). FSH and testosterone signaling in Sertoli cells. Reprod.130(1): 15-28. https://doi.org/10.1530/ rep. 1.00358

-Wennink JM, HA Delemarre-van de Waal, R Schoemaker, G Blaauw, C van den Braken, J Schoemaker (1990). Growth hormone secretion patterns in relation to $\mathrm{LH}$ and testosterone secretion throughout normal male puberty. Acta
Endocrinolog. 123(3): 263-270. https://doi.org/10.1530/ acta.0.1230263

-Weyler S. F Fülle, M. Diekmann, B Schumacher, S Hinz, KN Klotz,CE Müller (2006). Improving Potency, Selectivity, and Water Solubility of Adenosine A1 Receptor Antagonists: Xanthines Modified at Position 3 and Related Pyrimido [1, 2, 3-cd] purinediones. Chem. Med. Chem. 1(8): 891-902. https://doi.org/10.1002/cmdc.200600066

-Xin Z, MD Serby, H Zhao, C Kosogof, BG Szczepankiewicz, M Liu BoLiu, CW Hutchins, KA Sarris, ED Hoff (2006). Discovery and pharmacological evaluation of growth hormone secretagogue receptor antagonists. J. Med. Chem. 49(15): 4459-4469. https://doi.org/10.1021/jm060461g

-Zhou L, M Yang, S Zuo, X Guan, J Wang, Q Chen, X Zuo, S Jia, R Guo (2017). Dlitiazem inhibits the oxidative stress induced by angiotensin II through growth hormone secretagogue receptor type $1 \mathrm{a}$ in human umbilicus vein endothelial cells. Biomed. Pharmacotherap. 89: 76-82. https://doi.org/10.1016/j.biopha.2017.02.022 